\title{
Presentación. Seminario Internacional sobre Religiosidad Popular y espacio sagrado
}

El año 2002 la Facultad de Teología escogió el tema "Religiosidad popular y espacio sagrado" para su Seminario interno de profesores. Se quiso de este modo responder a la colaboración pedida por la Comisión Nacional de Pastoral de Multitudes, organismo dependiente del Episcopado chileno, que estaba encargada de organizar el Tercer Congreso Americano de Rectores de Santuarios, en noviembre de ese año.

De hecho, aportes realizados en este Seminario fueron de utilidad para los asistentes al Congreso. Se contó también con la participación, en la última sesión, del P. Miguel Camin, ex encargado pastoral del Santuario de la Virgen de Guadalupe, y responsable de una de las ponencias en el Congreso de Rectores.

Se consideró, además, que este Seminario era una buena oportunidad para continuar la serie de encuentros y seminarios realizados por la Facultad de Teología sobre el tema de la Religiosidad Popular a lo largo de estos últimos treinta años.

El primer Encuentro tuvo lugar entre los días 2 al 6 de diciembre de 1973 y contó con la participación de investigadores peruanos y argentinos. Los trabajos presentados en esa ocasión se recopilaron en el libro "Religiosidad y fe en América Latina”, Ed. Mundo, Santiago, 1975.

Un segundo Encuentro tuvo lugar entre los días 16 al 20 de mayo de 1977, que contó con la participación del Equipo Pastoral del Santuario Maipú y la presencia de teólogos, investigadores y pastores de Chile y América Latina. Lo planteado en esa ocasión está en el libro "Historia y Misión”, Ed. Mundo, Santiago, 1977.

Un tercer evento fue el Seminario Interdisciplinar sobre evangelización, cultura y religiosidad popular, realizado durante el año 1986 con ponencias interdisciplinares y participantes extranjeros. El seminario concluyó la primera semana de octubre con ponencias abiertas al público en general. La revista Teología y Vida $\mathrm{N}^{\mathbf{0}} 1-2$ de 1987, recogió lo presentado en esa ocasión.

Lo publicado en este número de Teología y Vida quiere ser un paso más en la reflexión de esta temática que continúa despertando valiosos interrogantes teológicos y pastorales para la Iglesia latinoamericana, como también suscitando el interés de otras disciplinas. Es por eso que este Seminario ha querido continuar manteniendo la dimensión internacional e interdisciplinaria de los anteriores encuentros. 
Es así, que queremos agradecer al Prof. Luis Flores H., actual decano de la Facultad de Filosofía de nuestra Universidad, y a la Prof. Sol Serrano, del Instituto de Historia, por haber aceptado participar y contribuir desde sus respectivas disciplinas a iluminar el tema de este Seminario.

También un especial reconocimiento al Prof. P. Carlos Galli, decano de la Facultad de Teología de la Universidad Católica de Argentina, quien generosamente aceptó venir a participar con nosotros y compartir una reflexión desde más allá de nuestras fronteras geográficas.

Extendemos nuestra gratitud a la docente Agustina Serrano, quien como coordinadora adjunta llevó a cabo con esmero todas las tareas encomendadas que hicieron posible la realización de este Seminario Interno.

Cristián Johansson F. Coodinador del Seminario Interno 